\title{
A study of the aetiological agents of childhood diarrhoea in Lagos, Nigeria
}

\author{
T. I. OGUNSANYA, V. O. ROTIMI* and A. ADENUGA†
}

Departments of Medical Microbiology and Parasitology, and † Paediatrics, College of Medicine of the University of Lagos, Idi Araba, PMB 120003, Lagos, Nigeria and *Division of Clinical Microbiology, King Fahd Armed Forces Hospital, PO Box 9862, Jeddah 21159, Kingdom of Saudi Arabia

\begin{abstract}
Summary. From December 1989 to May 1990, 315 faecal samples from children under 5 years old with diarrhoea (215) and without diarrhoea (100) seen at paediatric clinics were investigated for bacterial, viral and parasitic enteropathogens. Standard and recently described methods were used for the investigations, which revealed that $74.9 \%$ of children with diarrhoea were infected with enteropathogens compared with $28 \%$ of controls. In the diarrhoeal group, $59 \cdot 1 \%$ had a bacterial, $26.5 \%$ a viral and $2.3 \%$ a parasitic aetiology. Rotavirus was the pathogen most frequently detected, accounting for $22.3 \%$ of positive findings in the group with diarrhoea versus $9 \%$ in the control group. Other important agents were: enterotoxigenic Escherichia coli (ETEC) (14.4 versus 6\%), enteropathogenic E. coli (EPEC) $(10.7$ versus $5 \%)$, enteroadherent E.coli (EAEC) $(9.3$ versus $4 \%)$, enterohaemorrhagic E. coli (EHEC) $(5 \cdot 1$ versus $3 \%)$ and Salmonella spp. (3.3 versus $1 \%$ ). The following enteropathogens were detected exclusively in the diarrhoeal stools: Shigella spp. $(5 \cdot 1 \%)$, Yersinia enterocolitica $(0.9 \%)$, Aeromonas hydrophila $(1.4 \%)$, Entamoeba histolytica $(0.5 \%)$, Giardia lamblia $(0.5 \%)$, Trichomonas hominis $(0.5)$ and Trichuris trichiura $(0.9 \%)$. The detection rates of rotavirus, EPEC and EAEC were much greater in the diarrhoeal than in the control patients. No Vibrio cholerae, enteroinvasive E. coli (EIEC), Plesiomonas spp. or Cryptosporidum spp. were detected in this study. Our data suggest that both the traditional and newly recognised diarrhoeal agents are important causes of diarrhoea in the children under 5 years old in Lagos, Nigeria.
\end{abstract}

\section{Introduction}

Diarrhoea poses a very serious problem in developing countries where it is the leading cause of morbidity and mortality amongst children. ${ }^{1-3}$ It ranks second as a major cause of morbidity among the notifiable diseases in Nigeria ${ }^{2}$ where, according to the Federal Statistic Bulletin, ${ }^{4}$ c. 300 children die every day from dehydration and malnutrition caused by diarrhoea. This could be an underestimate, as very few patients have access to the very limited number of hospitals and health centres that are available.

Aetiological agents of diarrhoea are many and varied. In Nigeria, data from various studies have implicated various enteropathogens ${ }^{.5-10}$ However, the relative occurrence of these pathogens in the defined age group most vulnerable to enteropathogenic infections has not been well documented. Therefore, it is difficult to generalise about the public health importance of these agents in children under 5 years old in Nigeria. Furthermore, the roles of relatively "new"

Received 14 Feb. 1993; accepted 8 June 1993

*Correspondence should be sent to Professor V. O. Rotimi. agents such as enterohaemorrhagic Escherichia coli (EHEC), enteroadherent E. coli (EAEC), Plesiomonas spp. and cryptosporidia in childhood diarrhoea in Nigeria still need to be investigated properly.

This study was undertaken to investigate the prevalence of enteropathogens and the role of newly recognised pathogens in diarrhoea amongst children under 5 years of age in Lagos.

\section{Materials and methods}

\section{Patient population}

Between December 1989 and May 1990, faecal specimens were obtained from children aged $\leqslant 5$ years attending the Paediatric Emergency Room, Lagos University Teaching Hospital (LUTH), and the Children's Clinic at Gbaja Health Centre, Surulere, about $1 \mathrm{~km}$ from LUTH; 215 specimens were collected from children with acute diarrhoea. During the same period 100 faecal specimens, collected from agematched children seen at the same hospitals for reasons other than gastrointestinal illness, were selected as controls. Neither patients nor controls had received 
antibiotics in the preceeding 2 weeks. Detailed history to define age, sex, current diarrhoeal illness and frequency of bowel motions was documented carefully. Stool specimens were collected by one of us (T.I.O.) who noted the consistency and presence of frank blood or mucus or both. Specimens were transported in stool cartons to the laboratory where they were examined immediately by microscopy for the presence of red blood cells and leucocytes, and then examined for bacterial, viral and parasitic enteropathogens. All the specimens were processed within $2 \mathrm{~h}$ of collection.

\section{Cell lines}

Enterotoxin production and enteroadherent properties of $E$. coli were determined by assays with Vero and HEp-2 cell lines obtained from Yaba Vaccine Production Laboratories, Yaba, Lagos.

\section{Animals}

Suckling mice weighing c. $2.5 \mathrm{~g}$ and guinea-pigs weighing $c .500 \mathrm{~g}$ were obtained from the University of Lagos College of Medicine for the investigation of the toxigenic and invasive properties of the enteropathogens. They were housed in filter-topped cages and were fed with rat chow and water ad libitum.

\section{Microbiological methods}

Faecal samples were cultured for pathogenic $E$. coli, salmonellae, shigellae, aeromonads, Plesiomonas spp., vibrios and yersiniae on the following media (Unipath): MacConkey Agar, Sorbitol MacConkey Agar for E. coli O157:H7, Desoxycholate Citrate Agar (DCA), Xylose Desoxycholate Citrate Agar (XDCA), Salmonella-Shigella Agar (SS) and Thiosulphate Citrate Bile Salt (TCBS) Agar. Specimens were also inoculated into phosphate-buffered saline (PBS), alkaline peptone water ( $\mathrm{pH} \mathrm{8.6)} \mathrm{and} \mathrm{selenite-F}$ broth. All inoculated media were incubated at $37^{\circ} \mathrm{C}$ for 18-24 h. Cold enrichment for Yersinia spp. in Dulbecco's PBS (Unipath) at $4{ }^{\circ} \mathrm{C}$ was performed on all specimens, which were thereafter subcultured on to MacConkey agar and DCA after 7,14 and 21 days and incubated at room temperature. The alkaline peptone water was subcultured on to TCBS agar and XDCA, and selenite- $F$ broth cultures were subcultured on to DCA and SS agar. These subcultures were also incubated at $37^{\circ} \mathrm{C}$ for $18-24 \mathrm{~h}$. Representative colonies were selected and isolates were identified by standard methods. ${ }^{11.12}$ For $E$. coli, five colonies were selected randomly from each plate for testing.

All Salmonella spp., Shigella spp. and E. coli isolates were serotyped with Wellcome Diagnostic Antisera. $E$. coli isolates, whether sorbitol negative or not, were kept on nutrient agar slopes at room temperature for a period of up to 6 months. These storage conditions appeared to be suitable for the marker plasmids of
E. coli $\mathrm{K} 12$. They were then screened for toxin production by a modified Vero cell line assay. ${ }^{13}$

Heat-stable enterotoxigenic strains of E.coli (ETEC) were confirmed by the suckling mouse test described by Giannella. ${ }^{14} \mathrm{~A}$ mean ratio of the intestinal weight to the weight of the remaining carcase of $\geqslant 0.083$ was taken to indicate the presence of heat-stable enterotoxin. The heat labile ETEC strains were identified by the modification of the Elek test described by Honda et al. ${ }^{15}$ while the enteroinvasive strains of the $E$. coli (EIEC) isolates were identified by the Sereny test for invasiveness in the guinea-pig eye model. ${ }^{16}$

The enteroadherent $E$. coli (EAEC) strains were identified by testing for adherence to HEp- 2 cell lines. ${ }^{17}$ For each strain, the pattern of adherence was noted, i.e., diffuse, localised or aggregative.

Wet mounts of each fresh faecal sample were made in saline and iodine solution and examined for trophozoites and cysts of Entamoeba histolytica and Giardia lamblia. Formalin-ether concentrates (FEC) and smears stained with iron haemotoxylin were also prepared for each specimen and examined for other intestinal parasites. Another smear prepared from the FEC was stained by modified Kinyoun acid-fast stain and examined for cryptosporidial oocysts.

Rotavirus was detected by preparing a $10 \%$ suspension of each faecal sample in PBS (pH 7.4) and centrifuging at $2000 \mathrm{~g}$ for $15 \mathrm{~min}$. The faecal supernate collected was tested for the presence of rotavirus antigen with an ELISA technique. ${ }^{18}$

\section{Results}

The comparative characteristic features of both the patients and controls are shown in table I: $166(77 \%)$ of the 215 children with diarrhoea were aged $\leqslant 1$ year; $98.4 \%$ of them were aged $\leqslant 3$ years. None was above 4 years old. The sex distribution showed a male: female ratio of $2: 1$. Over $60 \%$ of diarrhoeal patients sought medical help within the first 7 days of the onset of symptoms; $46 \%$ were febrile, $4 \%$ and $14 \%$ had

Table I. Comparative characteristics among the diarrhoeal patients and control subjects

\begin{tabular}{lcc}
\hline Presenting features & $\begin{array}{c}\text { Patient group } \\
(215)\end{array}$ & $\begin{array}{c}\text { Control group } \\
(100)\end{array}$ \\
\hline Age in months & & \\
$\quad$ Range & $2-48$ & $6-48$ \\
$\quad$ Mean & $11 \cdot 4$ & $15 \cdot 0$ \\
Male: female ratio & $2: 1$ & $1 \cdot 9: 1$ \\
Time of seeking medical & & \\
assistance & $131(60 \cdot 9 \%)$ & $\ldots$ \\
$\quad$ 1 week & 84 & $\ldots$ \\
$\quad>1$ week & $90(46 \%)$ & $\ldots$ \\
Fever & $9(4 \cdot 2 \%)$ & 0 \\
Presence of blood & $30(14 \%)$ & $3(3 \%)$ \\
$\quad$ Frank & $103(47.9 \%)$ & $9(8 \%)$ \\
$\quad$ Microscopic & & \\
Presence of leucocytes & & \\
$\quad$ on microscopy & & \\
\hline
\end{tabular}


Table II. Detection of enteropathogens in diarrhoeal patients and controls

\begin{tabular}{lcc}
\hline & \multicolumn{2}{c}{ Number $(\%)$ of positive results from } \\
\cline { 2 - 3 } Enteropathogen & $\begin{array}{c}\text { diarrhoeal group } \\
(215)\end{array}$ & $\begin{array}{c}\text { control group } \\
(100)\end{array}$ \\
\hline EPEC & $23(10 \cdot 7)$ & $5(5)$ \\
ETEC* & $31(14 \cdot 4)$ & $6(6)$ \\
EHEC & $11(5 \cdot 1)$ & $3(3)$ \\
EAEC & $20(9 \cdot 3)$ & $4(4)$ \\
Salmonella spp. & $7(3 \cdot 3)$ & $1(1)$ \\
Shigella spp. & $11(5 \cdot 1)$ & $0(0)$ \\
$Y$. enterocolitica & $2(0 \cdot 9)$ & $0(0)$ \\
A. hydrophila & $3(1 \cdot 4)$ & $0(0)$ \\
Ent. histolytica & $1(0 \cdot 5)$ & $0(0)$ \\
G. lamblia & $1(0 \cdot 5)$ & $0(0)$ \\
T. hominis & $1(0 \cdot 5)$ & $0(0)$ \\
Trichuris trichiura & $2(0 \cdot 9)$ & $0(0)$ \\
Rotavirus & $48(22 \cdot 3)$ & $9(9)$ \\
& & \\
\hline
\end{tabular}

${ }^{*}$ Enterotoxin type in patients: LT $6(2.8 \%)$; ST $23(10.7 \%)$; LT/ST $2(0.9 \%)$. The six strains from the control group were ST-positive.

frankly bloody stools or red cells on microscopy, respectively. The control and the diarrhoeal cases were fairly well matched. For the control group, the mean age was 1.3 years, the male:female ratio $1.9: 1$ and its members belonged to a similar economic background and residential area.

\section{Aetiological agents}

One hundred and sixty-one (74.9\%) of the 215 diarrhoeal stools and $28(28 \%)$ of control specimens yielded pathogens. All the positive diarrhoeal stools and 25 of the 28 control stools contained single pathogens. The individual enteropathogens isolated in the patient and control groups are shown in table II.

ETEC strains were the most commonly isolated bacterial pathogen, particularly in children with diarrhoea ( $14.4 \%$ yielded ETEC): LT-producing ETEC strains were isolated from six stools, STproducing strains from 29 and LT- and ST-producing strains from two. The mean age of diarrhoeal patients infected with ETEC strains was 9 months. By contrast, the mean age of the control children from whom ETEC strains were isolated was $30 \cdot 1$ months. EPEC was the second most common bacterial agent isolated, being found in 23 diarrhoeal and five control patients. EPEC serotypes $\mathrm{O} 26$ and $\mathrm{O} 86$ were detected in both patients and controls; serotypes O55, O111, O125, $\mathrm{O} 128$ and $\mathrm{O} 18 \mathrm{c}$ were detected in the patients only. The most frequently isolated serotype was O55 (10 of $28: 35 \cdot 7 \%$ ) followed by $\mathrm{O} 125$ ( 5 of $28: 17 \cdot 8 \%$ ). None of the EPEC strains exhibited adherence to the HEp-2 cells. EAEC strains were detected in 20 patients and four controls: 14 exhibited aggregative type adherence on HEp-2 cells, six exhibited localised adherence and the remaining four showed the diffuse type of adherence. None of the EAEC strains belonged to any EPEC serogroups frequently associated with this phenotype. EHEC strains were isolated from 11 patients and three controls; the former were $<1$ year old whereas the latter were $>2$ years old. No EIEC strains were isolated during this survey.

The distribution of the other bacterial pathogens isolated from patients and controls showed that the majority of them were exclusively isolated from the patients. Only the salmonellae were isolated from both patients and controls; seven and one isolates, respectively. The majority ( 4 of 7) were detected in patients $<1$ year old. The eight Salmonella isolates were identified as serotypes typhimurium (4), paratyphi A (2) and typhi (2). The mean age of patients infected with salmonellae was 12.0 months. The Shigella spp. were isolated exclusively from children with diarrhoea (11 isolates). The age range of the patients was 3-48 months with a mean of 21.0 months. Of the 11 isolates five $(45 \cdot 4 \%)$ were $S h$. flexneri, three $(27.3 \%) S h$. boydii, two (18.2\%) Sh. dysenteriae and one Sh. sonnei. $Y$. enterocolitica and Aeromonas hydrophila were isolated from two and three patients respectively.

Overall, the commonest enteropathogen detected was rotavirus - detected in $48(22.3 \%)$ patients and nine $(9 \%)$ controls. Forty-five $(93.8 \%)$ of the 48 rotavirus isolates were detected in patients under 2 years old with a mean age of $12 \cdot 2$ months. The four types of intestinal parasites isolated were mainly from the patient group; E. histolytica (1) G. lamblia (1), Trichomonas hominis (1) and Trichuris trichiura (2). Vibrio cholerae was not isolated from either patients or controls in this study.

\section{Discussion}

Previous studies in Lagos have documented the prevalence of some traditionally recognised agents of diarrhoea ${ }^{5,9,10}$ but none has reported the prevalence of the newly recognised agents of diarrhoea, such as enteroadherent $E$. coli (EAEC) or enterohaemorrhagic E. coli (EHEC). Furthermore, our study has highlighted pertinent presenting features, such as fever, duration of illness before seeking hospital attention and the presence of red and white blood cells in the faeces, and shown that the majority of urban patients under 5 years of age with diarrhoea sought medical attention within the first week of their illness.

Both the heat-labile toxin-producing ETEC $\left(\mathrm{LT}^{+}\right)$ and heat-stable toxin-producing ETEC $\left(\mathrm{ST}^{+}\right)$are recognised causal agents of diarrhoea worldwide. ${ }^{18-22}$ $\mathrm{ST}^{+}$ETEC strains were isolated with equal frequency from the diarrhoeal and the control groups whereas $\mathrm{LT}^{+}$ETEC strains, though detected in fewer patients, were confined to the diarrhoeal group only. This suggests that in the urban population of patients in Lagos the $\mathrm{LT}^{+}$-producing ETEC strains are probably more associated with diarrhoea than the $\mathrm{ST}^{+}$ETEC strains. However, a much larger study conducted over a longer period may be needed to confirm this tentative conclusion, especially as studies from some other developing countries have indicated that the carriage 
of $\mathrm{LT}^{+}$strains of ETEC is not statistically associated with diarrhoea. ${ }^{23-25}$ Although $\mathrm{ST}^{+}$strains of ETEC were strongly associated with diarrhoea in studies conducted in a similar setting in $\mathrm{China}^{26}$ and Australia, ${ }^{27}$ our survey showed a relatively high carriage rate of $\mathrm{ST}^{+}$strains in the control group, which makes interpretation somewhat difficult. A study from Djibouti ${ }^{25}$ appears to be in agreement with our experience. The observation in this survey of a decreasing isolation rate of ETEC strains with age is also of interest; the majority of the diarrhoeal patients with ETEC were $<1$ year old whereas the average age among the controls carrying ETEC strains was 30.1 months, thus confirming the experience in Mogadishu. ${ }^{28}$

So far as we know, this report represents the first description of EHEC $(\mathrm{O} 157: \mathrm{H} 7)$ and EAEC in patients with diarrhoea in Nigeria. Finding these two newly described diarrhoeal pathogens in our patients in a relatively higher proportion than that which has been reported in many developed countries ${ }^{29,30}$ is of great clinical importance. EHEC strains have been strongly associated with watery diarrhoea, haemorrhagic colitis and the haemolytic uraemic syndrome. ${ }^{31,32}$ However, more reports on studies conducted in other developing countries are necessary to determine whether or not there is significant geographic difference in the prevalence of EHEC and EAEC infections. Similar high isolation rates of EHEC to that in our study $(5.1 \%)$, have been reported from Asian countries, i.e., $7 \%$ of patients in Thailand ${ }^{33}$ and $6.8 \%$ of patients in Beijing. ${ }^{26}$ Surprisingly, a lack of association between a history of faecal blood and the presence of microscopic faecal leucocytes was found with the isolation of our EHEC strains. None of the EAEC strains isolated from both patients and controls belonged to the recognised EPEC serogroups, just as none of the EPEC isolates were enteroadherent, which confirms the finding of Mikhail et al..$^{25}$

Many of the patients from whom EAEC strains were isolated in this study, as in two other reports, ${ }^{24,26}$ presented with fever, or faecal leucocytes and erythrocytes. These features are more frequently associated with invasive diarrhoeal pathogens and support the in-vitro observations of Donnenburg et al. ${ }^{34}$ who showed that EAEC strains were not only enteroadhesive but also invasive towards epithelial cells. EAEC strains exhibiting localised adherence to $\mathrm{HeLa}$ or $\mathrm{HEp}-2$ cell lines in vitro have been associated consistently with diarrhoea all over the world. ${ }^{26,35,36}$ This survey confirms that EAEC is positively associated with diarrhoea in children between 1 and 2 years old, an age higher than that usually associated with ETEC infection.

\section{References}

1. Walsh JA, Warren KS. Selective primary health care. An interim strategy for disease control in developing countries. $N$ Engl J Med 1979; 301: 967-974.
Our data show that EPEC is the second most common bacterial diarrhoeal pathogen isolated from both patients and controls after ETEC, although more frequently isolated from patients, which is similar to a report from South Africa. ${ }^{37}$ The isolation rate of EPEC strains in diarrhoeal patients in Lagos remains consistently and relatively high. Previous studies ${ }^{5,38}$ support this assertion. Over $78 \%$ of the patients infected with EPEC strains were aged $\leqslant 2$ years with an average age greater than that found with ETEC or EAEC infections. The preponderance of EPEC in the older age group in our survey is in contrast to observations in the developed countries, where neonates are the most vulnerable age group. ${ }^{39}$ This may be related in part to the delayed weaning normally practised in developing countries. ${ }^{40}$

Other bacterial pathogens, (Shigella spp., Salmonella spp., A. hydrophila and $Y$. enterocolitica) were confined mainly to the diarrhoeal group. We may assume that these bacteria are indeed pathogenic whenever they are found in the stool specimens of children with diarrhoea in Lagos. All patients with shigella infection had fever and faecal erythrocytes on microscopy. The mean age of these patients was 18 months. Our finding with shigellae is similar to the reports from Djibouti, ${ }^{25}$ Beijing ${ }^{26}$ and Somalia ${ }^{28}$ with regards to species prevalence and positive association with faecal leucocytes and erythrocytes. The commonest species in our survey, as in these other reports, was Sh. flexneri.

The results of this study are in agreement with many other reports from elsewhere, ${ }^{95,41,42}$ in that rotavirus is the most frequent cause of diarrhoea in the defined age group that we surveyed. The overall attack rate of c. $22 \%$ in the diarrhoeal group compares with the reported rates of $19-27 \%$ in other countries. Children afflicted with diarrhoea caused by rotavirus were $<2$ years old and leucocytes and erythrocytes were not present in their faeces.

The yield from examination of stools for cysts, ova and parasites was very low. No cryptosporidial oocysts were found. Limited information from Nigeria suggests that Crytosporidium spp., G. lamblia and other parasitic infections are rare causes of diarrhoea. ${ }^{43.44}$ This low yield may also be explained by the limitations of detection from a single faecal specimen, the small quantity of samples obtained from some patients and the timing of the study. The survey was conducted during the dry season of the year and occurrence of G. lamblia, Ent. histolytica and Cryptosporidium spp. may be seasonal, as is generally the case in temperate countries, appearing more in the rainy season.

We thank Mrs Macaulay for her technical assistance and Ms Sheila Baker for her excellent secretarial assistance.

2. Barua D. The WHO Global Diarrhoeal Disease Control programme. In: Emejuaiwe SO, Ogunbi O, Sanni SO (eds) Global impacts of applied microbiology (Sixth international conference). London, Academic Press. 1981: 405-413. 
3. Synder JD, Merson MH. The magnitude of the global problem of acute diarrhoeal disease: a review of active surveillance data. Bull World Health Organ 1982; 60: 605-613.

4. Federal Ministry of Health Bulletin. Lagos Statistics. Lagos, Government Press. 1987: 20, 5.

5. Ogunbi O, Hunponu-Wusu OO, Coker AO et al. Bacterial and viral agents associated with diarrhoeal diseases in LagosNigeria. In: Emejuaiwe SO, Ogunbi O, Sanni SO (eds) Global impacts of applied microbiology (Sixth international conference). London, Academic Press. 1980: $427-434$

6. Agbonlahor DE, Odugbemi TO, Lasi Q. Isolation of Yersinia enterocolitica from stools of acute gastroenteritis cases in Lagos, Nigeria. East Afr Med J 1981; 58: 520-524.

7. Olusanya O, Adebayo JO, Williams B. Campylobacter jejuni as a bacterial cause of diarrhoea in Ile-Ife, Nigeria. $J \mathrm{Hyg}$ 1983; 91 : 77-80.

8. Coker AO, Dosunmu-Ogunbi O. Isolation of Campylobacter jejuni in Lagos, Nigeria-a new bacterial agent of diarrhoea. East Afr Med J 1984; 61 : 52-55.

9. Coker AO, Dosunmu-Ogunbi O, Odugbemi T et al. A study on the prevalence of rotavirus diarrhoea in Ohoazara Local Government area, Imo State, Nigeria and Lagos University Teaching Hospital, Nigeria. East Afr Med J 1987; 64: 587-589.

10. Oyerinde JPO, Dosunmu-Ogunbi O, Alonge AA. Age and sex distribution of infections with Entamoeba histolytica and Giardia intestinalis in Lagos population. Int $J$ Epidemiol 1977; 6: 231-234.

11. Kelly MT, Brenner DJ, Farmer JJ. Enterobacteriacae. In Lennette EH, Balows A, Hansler WJ, Truant JP (eds) Manual of clinical microbiology. Washington, DC, American Society for Microbiology. 1985: 263.

12. Cowan ST, Steel KJ. Identification of medical bacteria, 2nd edn. London, Cambridge University Press. 1974.

13. Pai CH, Gordon R, Sims HV, Bryan LE. Sporadic cases of haemorrhagic colitis associated with Escherichia coli O157: H7-Clinical, epidemiologic and bacteriologic features. Ann Intern Med 1984; 101: 738-742.

14. Giannella RA. Suckling mouse model for detection of heatstable Escherichia coli enterotoxin:characteristics of the model. Infect Immun 1976; 14: 95-99.

15. Honda T, Taga S, Takeda Y, Miwatani T. Modified Elek test for detection of heat-labile enterotoxin of enterotoxigenic Escherichia coli. J Clin Microbiol 1981; 13: 1-5.

16. Sereny B. Experimental shigella keratoconjunctivitis-a preliminary report. Acta Microbiol Acad Sci 1955; 2: 293-296.

17. Matthewson JJ, Johnson PC, Dupont HL et al. A newly recognized cause of travelers' diarrhea: enteroadherent Escherichia coli. J Infect Dis 1985; 151 : 471-475.

18. Yolken RH, Wyatt RG, Kapikian AZ. ELISA for rotavirus. Lancet 1977; 2: 819

19. Echeverria P, Taylor DN, Suthienkul O. Recent advances in bacterial diarrhoea. Southeast Asian J Trop Med Public Health 1986; 17: 627-634.

20. Shukry S, Zaki AM, DuPont HL, Shoukry I, El Tagi M, Hamed Z. Detection of enteropathogens in fatal and potentially fatal diarrhea in Cairo, Egypt. J Clin Microbiol 1986; 24 : 959-962.

21. Levine MM. Escherichia coli that causes diarrhoea: enterotoxigenic, enteropathogenic, enteroinvasive, enterohemorrhagic and enteroadherent. $J$ Infect Dis $1987 ; 155: 377-389$.

22. Ako-Nai AK, Laminkanra A, Ola O, Fadero FF. A study of the incidence of enterotoxigenic Escherichia coli (ETEC) secreting heat-labile toxin in two communities in southwestern Nigeria. J Trop Med Hyg 1990; 93: 116-118.

23. Escheverria P, Taylor DN, Lexsomboon U et al. Case-control study of endemic diarrhoeal disease in Thai children. $J$ Infect Dis 1989; 159: 543-548.

24. Kim K-H, Suh I-S, Kim JM, Kim CW, Cho Y-J. Etiology of childhood diarrhea in Korea. J Clin Microbiol 1989; 27 : 1192-1196.
25. Mikhail IS, Fox E, Haberberger RL, Ahmed MH, Abbatte EA Epidemiology of bacterial pathogens associated with infectious diarrhea in Djibouti. J Clin Microbiol 1990; 28: 956-961.

26. Kain KC, Barteluk RL, Kelly MT et al. Etiology of childhood diarrhea in Beijing, China. J Clin Microbiol 1991; 29: 90-95.

27. Valladares KD. Enteric pathogens in aboriginal and nonaboriginal children admitted to Port Augusta Hospital. Aust J Med Lab Sci 1990; 11: 93-95.

28. Casalino M, Yusuf MW, Nicoletti M et al. A two-year study of enteric infections associated with diarrhoeal diseases in children in urban Somalia. Trans $R$ Soc Trop Med Hyg $1988 ; 82 ; 637-641$.

29. Pai CH, Ahmed N, Lior H, Johnson WM, Sims HV, Woods DE. Epidemiology of sporadic diarrhea due to verocytotoxin-producing Escherichia coli: a two-year prospective study. J Infect Dis 1988; 157: 1054-1057.

30. Harris AA, Kaplan RL, Goodman LJ et al. Results of a screening method used in a 12-month stool survey for Escherichia coli O157: H7. J Infect Dis 1985; 152: 775-777.

31. Spika JS, Parsons JE, Nordenberg D, Wells JG, Gunn RA, Blake PA. Haemolytic ureamic syndrome and diarrhea associated with Escherichia coli $0157:$ H7 in a day care centre. J Pediatr 1986; 109: 287-291.

32. Remis RS, MacDonald KL, Riley LW et al. Sporadic cases of haemorrhagic colitis associated with Escherichia coli O157: H7. Ann Intern Med 1984; 101: 624-626.

33. Brown JE, Echeverria P, Taylor DN et al. Determination by DNA hybridization of Shiga-like-toxin-producing Escherichia coli in children with diarrhea in Thailand. J Clin Microbiol 1989; 27: 291-294.

34. Donnenberg MS, Donohue-Rolfe A, Keusch GT. Epithelial cell invasion: an overlooked property of enteropathogenic Escherichia coli (EPEC) associated with the EPEC adherence factor. $J$ Infect Dis $1989 ; 160: 452-459$.

35. Chatkaeomorakot A, Echeverria P, Taylor DN et al. HeLa celladherent Escherichia coli in children with diarrhea in Thailand. J Infect Dis 1987; 156: 669-672.

36. Mathewson JJ, Oberhelman RA, Dupont HL, de la Cabada FJ, Garibay EV. Enteroadherent Escherichia coli as a cause of diarrhea among children in Mexico. J Clin Microbiol 1987; 25: $1917-1919$.

37. Koornhof HJ, Robins-Browne RM, Richardson NJ, Canel R. Etiology of infantile enteritis in South Africa. Isr J Med Sci 1979; 15: 341-347.

38. Dosunmu-Ogunbi O. Intestinal microbial and helminthics infections, Lagos University Teaching Hospital, 1965-1968. J Niger Med Assoc 1971; 1: 53-59.

39. World Health Organization Scientific Working Group. Escherichia coli diarrhoea. Bull World Health Organ 1980; 58: $23-36$.

40. Rowe B. Enteropathogenic Escherichia coli (EPEC)importance and pathophysiology. In: Holme T, Holmgren $\mathrm{J}$, Merson MH, Möllby R (eds) Acute enteric infections in children: new prospects for treatment and prevention. Amsterdam, Elsevier. 1981: 101-107.

41. Escheverria P, Blacklow NR, Vollet JL et al. Rotavirus-like agent and enterotoxigenic Escherichia coli infections in paediatric diarrhea in the Philippines. J Infect Dis 1978; 138: 326-332.

42. Stintzing G, Bäck E, Tufvesson B, Johnsson T, Wadström X, Habte D. Seasonal fluctuations in the occurrence of enterotoxigenic bacteria and rotavirus in paediatric diarrhoea in Addis Ababa. Bull World Health Organ 1981; 59: 67-73.

43. Oyerinde JP, Odugbemi T, Benson RI et al. Investigation of Cryptosporidium in relation to other intestinal parasites at the Lagos University Teaching Hospital. W Afri J Med $1989 ; 8: 264-269$.

44. Eko FO, Rotimi VO. Cryptosporidium and Cryptosporidiosis: an epidemiologic and clinical review. Niger Med Practit 1992; 23: 17-21. 